\title{
Psychometric Properties of the Persian Version of the Vancouver Obsessional-Compulsive Inventory Inventory (VOCI) in Iranian Non-Clinical Sample
}

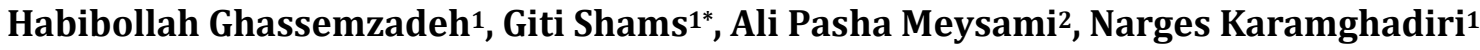 \\ ${ }^{1}$ Roozbeh Hospital, Department of Psychiatry, Tehran University of Medical Sciences, Tehran, Iran \\ ${ }^{2}$ Medical Faculty, Tehran University of Medical Sciences, Tehran, Iran \\ Email: ^shamsgit@tums.ac.ir
}

How to cite this paper: Ghassemzadeh, H., Shams, G., Meysami, A. P., \& Karamghadiri, N. (2017). Psychometric Properties of the Persian Version of the Vancouver Obsessional-Compulsive Inventory Inventory (VOCI) in Iranian Non-Clinical Sample. Psychology, 8, 206-225.

http://dx.doi.org/10.4236/psych.2017.81012

Received: May 4, 2016

Accepted: January 17, 2017

Published: January 20, 2017

Copyright () 2017 by authors and Scientific Research Publishing Inc. This work is licensed under the Creative Commons Attribution International License (CC BY 4.0).

http://creativecommons.org/licenses/by/4.0/

\begin{abstract}
The Vancouver Obsessional-Compulsive Inventory (VOCI) is a self-report inventory developed to assess a wide range of Obsessive-Compulsive symptoms. The aim of this study was to investigate psychometric properties of the Persian version of the VOCI in non-clinical samples. A questionnaire package including the VOCI, BDI-II, BAI, MOCI, OCI-R and PSWQ was administered to volunteer undergraduate students $(\mathrm{n}=233,139$ females, 94 males) from two Iran universities (Tehran University of Medical Sciences and Allameh Tabatabaei University). All the assessments were repeated in the same sample after 2 weeks. Psychometric analyses were run to assess reliability and validity of the Persian version of the VOCI. We converged an exploratory factor analysis to test the factor structure. The VOCI-Persian had good internal consistency, test-retest reliability, convergent and divergent validity. The present study showed that the factor structure of the questionnaire consisted of five main factors: VOCI Contamination, Checking, Obsessions, Hoarding and Perfectionism/Indecisiveness. Further studies are needed to develop psychometric tools with stronger diagnostic performance for OCD assessment.
\end{abstract}

\section{Keywords}

OCD, VOCI-Persian, Psychometric Properties, Exploratory Factor Structure

\section{Introduction}

The importance of using reliable and valid symptom measures of obsessivecompulsive disorder (OCD) in both research and clinical settings is widely recognized. Use of the measures (e.g. rating scales) enhances the quality of research 
projects as well as clinical services by clarifying the concepts on the one hand and refining the evaluation and documentation of a patient's state, on the other (Goodman, Lawernce, \& Price, 1998: p. 97). Some of scales are observer-rated scales such as Yale-Brown Obsessive-Compulsive Scale (Y-BOCS) and Compulsive Activity Checklist (CAC) and others are self-report measures such as Maudsley Obsessional-Compulsive Inventory (MOCI), Padua Inventory (PI), Leyton Obsessional Inventory (LOI), and Obsessional-Compulsive Inventory (OCI) (St. Clare, 2003).

One of the most important advantages of self-report instruments is the fact that they can be easily integrated into clinical practice to assess symptom presence and severity, and monitor treatment progress (Storch, Benito, \& Goodman, 2011). For that reason, in the last decade, a variety of multidimensional self-report measures have been published, designed to extensively cover the heterogeneous symptom spectrum of OCD. The main problem with these measures, however, is in the lack of general consensus about the content, number and structure of symptom dimensions. Contamination/washing, symmetry/ordering and hoarding have been replicated consistently across factor-analytic studies, but some dimensions (such as checking, harming obsessions and immoral obsessions) need further study. It is also unclear whether they form a common factor or separate dimensions (for a review, see Leckman et al., 2007). Therefore, working on the multidimensional OCD measures with valid symptom subscales and with satisfying psychometric properties is the potential to improve symptom-specific screening and treatment planning (Gönner, Ecker, Leonhart, \& Limbacher, 2010).

\subsection{The MOCI and Recent Studies on VOCI}

Among all self-report measures, the Maudsley Obsessional-Compulsive Inventory (MOCI; Hodgson \& Rachman, 1977) is one of the measures widely used in OCD studies. It contains 30 items including four subscales for cleaning, checking, doubting/conscientiousness and obsessional slowness. It has adequate internal consistency, with good criterion, convergent and discriminant validity (e.g. Emmelkamp, Kraaijkamp, \& Vanden Hout, 1999; Richter, Cox, \& Direnfeld, 1994). However, its utility is limited by some crucial weaknesses. For example, it fails to measure important OCD symptom dimensions (e.g. symmetry and ordering, repugnant obsessions); it uses confusing reverse scoring and its dichotomous true/false response format is not suitable for the assessment of gradual change over time (Radomsky et al., 2006; Thordarson et al., 2004).

The Vancouver Obsessional-Compulsive Inventory (VOCI) was designed to improve and extend the MOCI. It assesses a wider range of OCD symptoms than previous self-report instruments (Radomsky et al., 2006; Thordarson et al., 2004). Thordarson et al. (2004) believe that with the revision of the MOCI, the VOCI was designed to provide assessment of a wider range of obsessions, compulsions, avoidance behavior, and personality characteristics of known or theoretical importance in OCD. The VOCI is supposed to assess the degree of symptom sever- 
ity on six dimensions: Contamination, Checking, Obsessions, Hoarding, Just Right and Indecisiveness. This questionnaire is the only multidimensional OCD measure assessing two new subscales namely Indecisiveness and Just Right. Indecisiveness has been regarded as an important feature of OCD (e.g. Abramowitz \& Foa, 1998), but as a measure of OCD symptoms is questionable because of the low OCD specificity of the construct demonstrated by previous research (Thordarson et al., 2004). Thordarson et al. (2004) described the contents of Just Right scale as doing things exactly right, following strict routines, repeating, memorizing, and concern with being perfect, and feeling compelled to count. Different research groups conceptualize incompleteness feelings/not just right experiences (like harm avoidance or anxiety) as an important affective-motivational underpinning for several compulsions (e.g. Summerfeldt, 2004), but not as a compulsion itself. It appears to be an advantage to measure motivational variables (like not just right experiences) separately with specific measures (e.g. Summerfeldt, Kloosterman, Parker, Antony, \& Swinson, 2001) instead of including them in symptom measures assessing the content of obsessions and compulsions.

The VOCI has shown to demonstrate excellent psychometric properties. Each item is rated on a five-point Likert-type scale to enhance its sensitivity to therapeutic change. All items refer to current concerns and behavior, and are positively cued, leading to easier administration, scoring, and interpretation. It includes items for cognitive domain. Currently, in addition, Thordarson et al. (2004) found mixed evidence for their convergent and discriminate validity of VOCI. In the OCD sample, the total score highly correlated with other multidimensional self-report measures of OCD and moderately correlated with measures of anxiety, depression, and worry. Convergent and discriminate validity were excellent for the Contamination and Checking subscales, but weaker for Obsessions. The discriminate validity of Hoarding was excellent as well, while its convergent validity was not examined. Internal consistency and test-retest reliability of the VOCI scores were excellent.

But in addition to the English version, the VOCI is available in German, Spanish, French, Persian, Chinese, and Italian (Radomsky et al., 2006). Arjona et al. (2009) examined the factorial structure and psychometric properties of the VOCI in two non-clinical Spanish samples. An exploratory factor analysis replicated the original six-factor structure. The Spanish VOCI showed to be a reliable measure with good convergent and divergent validity that assesses beliefs that are relevant to the obsessive-compulsive disorder. The French versions of the VOCI demonstrate similar and excellent psychometric properties to the English versions and are highly valid and reliable assessment tools for use in clinical and research applications in both languages (Radomsky et al., 2006).

\subsection{A Short History of MOCI in Iran}

A number of self-rating instruments of OCD have been translated into Persian (Farsi), and have been used in patient and non-patient populations. In two earlier studies (Ghassemzadeh et al., 2002, 2005a), we examined the OCD 
symptoms in two samples of Iranian OCD patients using Persian translations of MOCI. In these studies the mean scores on MOCI $(\mathrm{M}=15.73, \mathrm{SD}=5.63$ for first study and $\mathrm{M}=14.67, \mathrm{SD}=5.76$ for the second) were close to those reported in other settings. However, we encountered numerous problems in using MOCI in Iran. First, the patients did not easily understand some of the items. Especially the double-negative sentences (e.g. "I don't worry unduly about contamination if I touch an animal.") created some problems regarding their meaning as could be categorized in "yes" or "no" response format. Second, the true- false response format of MOCI made it difficult for many OCD patients suffering from "indecisiveness" to respond. Third, as Foa et al. (1998) suggested the items of the MOCI encompass only two of the behavioral compulsions (i.e. checking and washing) and do not measure specific obsessions other than contaminations (Ghassemzadeh et al., 2011). These difficulties with MOCI motivated us to translate and examine the feasibility of VOCI. Some other OCD measures (such as OCI-R, CAC, PI-WSUR, OBQ-44, IITIS) have also been translated into Persian and have been used successfully in different settings and different non-clinical and clinical groups in Iran (Ghassemzadeh et al., 2011; Shams et al., 2011, 2014; Radomsky et al., 2014).

The cross-cultural studies on OCD measures can detect and formulate the similarities and differences of factors involved in OCD concept across different cultures. Specifically, the study on VOCI within the Iranian culture can provide us with some domestic measures for further study of obsessive-compulsive disorder in Iranian society. It also may throw a new light on the theoretical aspects of OCD. Moving in this direction, the main goal of present study was to examine the psychometric properties and factor structure of the Persian version of VOCI in a sample of college students. We also examined the convergent and divergent validity of VOCI, specially its correlation with other questionnaires like, MOCI, OCI-R, BDI-II, BAI, and PSWQ.

\section{Research Methods}

\subsection{Participants}

The sample consisted of 223 undergraduate students (139 females, 94 males) from two Iran universities (Tehran University of Medical Sciences and Allameh Tabatabaei University). Ethical approval was obtained from the Ethics Committees of two universities. The average age of the total sample was 20.47 ( SD = 3.95).

\subsection{Research Materials}

\subsubsection{Vancouver Obsessional-Compulsive Inventory (VOCI)} (Thordarson et al., 2004)

The VOCI is a self-report measure of OCD symptoms. Unlike the Y-BOCS, it was not designed to measure the severity of OCD, but rather, it comprises an inventory of 55 OCD symptoms that are each rated on a 5-Likert scale. Rating is summed to yield score on six subscales: Contamination, Checking, Obsessions, Hoarding, Just Right Experiences and Indecisiveness. The original VOCI has 
been shown to have well to excellent psychometric properties.

\subsubsection{Maudsley Obsessional-Compulsive Inventory (MOCI) (Hodgson \& Rachman, 1977)}

The MOCI is a 30-item true/false questionnaire assessing OCD symptoms across four domains: Washing, Checking, Doubting/Conscientiousness, and Slowness. The total scale as well as the washing and checking subscales have been shown to have good test-retest reliability, internal consistency, known-groups validity, and convergent and discriminate validity (Taylor, 1995). Maximum scores for the five scales (total, checking, washing, slowness-repetition, and doubt-conscientious) are 30, 9, 11, 7, and 7 respectively. As mentioned earlier, this test has been used frequently and widely in Iran and yielded satisfactory psychometric properties (Ghassemzadeh et al., 2002, 2005a, 2005b).

\subsubsection{Obsessive-Compulsive Inventory-Revised (OCI-R)}

(Foa et al., 2002)

The OCI-R is an 18-item self-administered questionnaire designed to assess distress associated with obsessive-compulsive symptoms each item is rated on a five-point $(0$ - 4) Likert scale for distress or bother during the past month. The total score ranges from 0 to 72 . The Persian version of this test demonstrated very high internal consistency as well as high test-retest reliability. Convergent and divergent validity of the OCI-R-Persian total scale and subscales were satisfactory (Ghassemzadeh et al., 2011).

\subsubsection{Beck Depression Inventory-II-Persian Version (BDI-II) (Beck, Steer, \& Gabrin, 1988)}

BDI-II is the second edition of the widely used 21-item inventory, the BDI. Originally developed in 1960s (Beck et al., 1961), BDI-II was revised to approximate the DSM-IV criteria for major depression. Scores on each item range from 0 to 3, yielding a possible maximum total score of 63 . The Persian version of this test (BDI-II-Persian) is widely used in various settings in Iran. Its psychometric properties have been examined elsewhere (Ghassemzadeh et al., 2005c).

\subsubsection{Beck Anxiety Inventory (BAI) (Beck, Steer, \& Gabrin, 1988)}

The BAI is a 21-item self-report measure of clinical anxiety. Its validity and reliability have been well established (Beck, Epstein, Brown, \& Steer, 1988). Each item is descriptive of subjective, somatic, or panic related symptoms of anxiety and is scored on a scale from 0 to 3 , yielding total score from 0 to 63 . The Persian version of this test demonstrated very high internal consistency $(\alpha=0.92)$ and high test-retest reliability $(\mathrm{r}=0.83)$ (Kaviani \& Mousavi, 2008).

\subsubsection{Penn State Worry Questionnaire (PSWQ) (Meyer, Miller, Metzger, \& Borkovec, 1990)}

The PSWQ is a 16-item questionnaire designed to measure the tendency to worry, with a total score ranging from 16 to 240. It has demonstrated high internal consistency $(\alpha>0.85)$ and good convergent validity. It is valuable as a discriminating measure, as worries and obsessions have been both conceptually and 
empirically differentiated in the literature (e.g. Turner, Beidel, \& Stanley, 1992).

\subsection{Procedure}

All the tests were administered to the students in a group setting during a class session after a brief description of the purpose of the study. The students were told that the participation is voluntary and no payment or course credit was offered to the participants. The VOCI was administered first, followed by BDI-II, BAI, MOCI, OCI-R, and PSWQ. All the assessments were repeated in the same sample after 2 weeks.

\subsection{Data Analysis}

Means and standard deviations (SDs) were calculated and used as descriptive statistics in all of the measures and demographic variables. The association between different tests and their subscales test-retest reliability, and convergent and divergent validity between different scales were assessed by Pearson Correlation Coefficient. Internal consistency of scales and subscales was assessed by using Cronbach's alpha. For the purpose of defining potential different subscales in VOCI we used factor analysis with Principal Axis Factoring Extractive Method and QuartImax with Kaiser Normalization Rotation Method. Initial communalities (h2) statistics were calculated for each question in any derived component. Among self-report measures, there are valuable screening tools for the purpose of providing a valid, reliable, and useful measurement of the heterogeneous clinical picture. But none of these measures covers all of the dimensions and symptoms of obsessive-compulsive disorder comprehensively and/or psychometrically satisfactory characteristics.

\section{Results}

\subsection{Descriptive Statistics of the VOCI and Subscales}

Assuming the original six subscale structure the means and standard deviations of the Persian version of the VOCI (total and subscales) for males and females (separately and total) are presented in Table 1.

Our descriptive statistics as compared with the original report of VOCI (Thordarson et al., 2004) as well as French version of VOCI are presented in Table 2.

As the data in Table 1 show, there are some differences between males and females regarding the measure and standard deviations. But using independent samples $t$ test, none of those difference reach at a significant level $(P<0.05)$.

Table 2 shows the means and standard deviations of total and subscales of VOCI as have been reported in original study by Thordarson et al. (2004), the French version of VOCI (Radomsky et al., 2006), and the present study. In general, the table shows some agreements among three studies, but the VOCI total score in our study (39.30) is higher than the original study (36.37) and the French version (36.58) (Thordarson et al., 2004). Regarding the subscales the mean and standard deviation of obsessions subscale in our group $(9.02,8.27)$ is also higher than the other two groups $(5.52,5.97$ and 5.42, 6.58). 
Table 1. Means and standard deviations of Persian version of VOCI for males and females.

\begin{tabular}{cccc}
\hline Scale & $\begin{array}{c}\text { Male } \\
(\mathrm{N}=94)\end{array}$ & $\begin{array}{c}\text { Female } \\
(\mathrm{N}=139)\end{array}$ & $\begin{array}{c}\text { Total } \\
(\mathrm{N}=233)\end{array}$ \\
\cline { 2 - 4 } & Mean (SD) & Mean (SD) & Mean (SD) \\
\hline Contamination & $6.5(7.2)$ & $6.3(6.5)$ & $6.37(6.69)$ \\
Checking & $3.7(50.0)$ & $2.6(4.4)$ & $3.05(4.68)$ \\
Obsessions & $9.4(90.0)$ & $8.8(7.8)$ & $9.02(8.27)$ \\
Hoarding & $4.2(4.4)$ & $4.8(4.8)$ & $4.57(4.60)$ \\
Just Right & $11.5(7.6)$ & $10.7(6.4)$ & $11.05(7.09)$ \\
Indecisiveness & $5(4.4)$ & $5.4(4.5)$ & $5.25(4.45)$ \\
VOCI (total) & $40.4(31.7)$ & $38.7(27.2)$ & $39.30(28.85)$ \\
\hline
\end{tabular}

Table 2. Means and standard deviations of VOCI (total and subscales) as reported in the original, French, and Persian versions.

\begin{tabular}{cccc}
\hline \multirow{3}{*}{ Students } \\
\hline \multirow{2}{*}{ VOCI } & $\begin{array}{c}\text { Thordarson et al. } \\
(2004)\end{array}$ & $\begin{array}{c}\text { Radomsky et al. } \\
(2006)\end{array}$ & $\begin{array}{c}\text { Present study } \\
(2014)\end{array}$ \\
\cline { 2 - 4 } & $\mathrm{N}=200$ & $\mathrm{~N}=(202-282)$ & $\mathrm{N}=233$ \\
$\mathrm{M} \mathrm{(SD)}$ & $\mathrm{M}(\mathrm{SD}) / \mathrm{Test}$ & $\mathrm{M}(\mathrm{SD})$ \\
\hline VOCI (total) & $36.37(26.56)$ & $36.58(29.04)$ & $39.30(28.85)$ \\
Contamination & $7.31(6.82)$ & $5.76(6.54)$ & $6.37(6.69)$ \\
Checking & $3.16(4.27)$ & $4.22(5.55)$ & $3.05(4.68)$ \\
Obsessions & $5.52(5.97)$ & $5.42(6.58)$ & $9.02(8.27)$ \\
Hoarding & $5.61(4.90)$ & $5.34(5.34)$ & $4.57(4.60)$ \\
Just Right & $9.00(7.06)$ & $10.05(7.63)$ & $11.05(7.09)$ \\
Indecisiveness & $5.77(4.44)$ & $6.50(4.88)$ & $5.25(4.45)$ \\
\hline
\end{tabular}

\subsection{Correlations among VOCI Subscales}

Correlations between each of the subscales and the total scale of the VOCI as well as the Inter-correlations among the subscales are shown in Table 3. Correlations between each of the subscales and the total scale ranged from 0.698 (hoarding) to 0.889 (Just Right). Inter-correlations among the subscales ranged from 0.390 (checking and hoarding) to 0.705 (Contamination and Just Right). All the correlations were significant at 0.000 levels (Table 3 ).

\subsection{Test-Retest Reliability and Internal Consistency}

The two-week test-retest reliability was calculated using Pearson's correlation coefficients. Cronbach's alpha was calculated and used as the internal consistency of the VOCI total scale, as well at the subscales (Table 4). The VOCI total scale as well as its subscales demonstrated very high test - retest reliability and internal consistency. 
Table 3. Correlations among VOCI subscales and each scale with the VOCI total score.

\begin{tabular}{|c|c|c|c|c|c|c|c|}
\hline VOCI & Contamination & Checking & Obsessions & Hoarding & Just Right & Indecisiveness & VOCI-Total \\
\hline Contamination & 1 & $0.574^{*}$ & $0.575^{\star}$ & $0.479^{*}$ & $0.705^{\star}$ & $0.565^{\star}$ & $0.827^{\star}$ \\
\hline Checking & & 1 & $0.437^{\star}$ & $0.390^{*}$ & $0.653^{*}$ & $0.474^{\star}$ & $0.717^{\star}$ \\
\hline Obsessions & & & 1 & $0.459^{*}$ & $0.615^{\star}$ & $0.684^{\star}$ & $0.820^{*}$ \\
\hline Hoarding & & & & 1 & $0.572^{*}$ & $0.601^{*}$ & $0.698^{*}$ \\
\hline Just Right & & & & & 1 & $0.693^{*}$ & $0.889^{*}$ \\
\hline Indecisiveness & & & & & & 1 & $0.824^{*}$ \\
\hline
\end{tabular}

${ }^{\star} P<0.000$.

Table 4. Test-retest reliability and internal consistency of Persian version of VOCI (Total and subscales).

\begin{tabular}{cccc}
\hline VOCI $(\mathrm{N}=233)$ & Test-retest & $P$ value & Cronbach's alpha \\
\hline Contamination & 0.803 & $<0.001$ & 0.849 \\
Checking & 0.906 & $<0.001$ & 0.928 \\
Obsessions & 0.930 & $<0.001$ & 0.864 \\
Hoarding & 0.901 & $<0.001$ & 0.816 \\
Just Right & 0.796 & $<0.001$ & 0.802 \\
Indecisiveness & 0.813 & $<0.001$ & 0.821 \\
Total & 0.887 & $<0.001$ & 0.940 \\
\hline
\end{tabular}

\subsection{Convergent and Divergent Validity of the VOCI Total Scale and Subscales}

Convergent validity of the VOCI total scale and subscales was determined by correlating the VOCI with two other measure of OCD, namely the MOCI and OCI-R, which have been used in the previous studies of OCD with student samples in Iran (Ghassemzadeh et al., 2002, 2005b) (Table 5).

As can be seen from Table 5 and Table 6, the VOCI, MOCI and the VOCI, OCI-R correlations were higher than VOCI correlations with BDI-II, BAI, and PSWQ indicating that the VOCI possesses good convergent and divergent validity.

\subsection{Factor Structure of Persian Version of VOCI}

Exploratory Factor Analysis (EFA) was performed to determine the structural validity of VOCI questionnaire. Promax factor rotation with Kaiser Normalization used for data reduction in summary scored as subscales. Components with an Eigen value $>$ or $=1.5$ retained as sub scales. The critical threshold for selecting items of each component was at 0.4. Questions which belonged to more than one component, considered as a question of the component, which showed maximum correlation (Table 7). 
H. Ghassemzadeh et al.

Table 5. Convergent validity for the VOCI subscales and the total score.

\begin{tabular}{|c|c|c|c|c|c|c|c|}
\hline MOCI VOCI & Contamination & Checking & Obsessions & Hoarding & Just Right & Indecisiveness & Total \\
\hline Washing & 0.624 & 0.443 & 0.359 & 0.312 & 0.508 & 0.363 & 0.550 \\
\hline Checking & 0.340 & 0.686 & 0.048 & 0.136 & 0.361 & 0.181 & 0.342 \\
\hline Slowness & 0.082 & 0.093 & -0.155 & 0.051 & 0.168 & -0.036 & 0.034 \\
\hline Total & 0.587 & 0.665 & 0.385 & 0.378 & 0.662 & 0.454 & 0.647 \\
\hline \multicolumn{8}{|l|}{ OCI-R } \\
\hline Washing & 0.737 & 0.552 & 0.429 & 0.409 & 0.575 & 0.404 & 0.652 \\
\hline Checking & 0.506 & 0.870 & 0.464 & 0.346 & 0.589 & 0.485 & 0.666 \\
\hline Hoarding & 0.324 & 0.286 & 0.379 & 0.722 & 0.424 & 0.440 & 0.517 \\
\hline Ordering & 0.555 & 0.435 & 0.460 & 0.379 & 0.624 & 0.414 & 0.609 \\
\hline Neutralizing & 0.368 & 0.278 & 0.351 & 0.301 & 0.350 & 0.386 & 0.424 \\
\hline Total & 0.666 & 0.656 & 0.681 & 0.585 & 0.712 & 0.624 & 0.821 \\
\hline
\end{tabular}

Table 6. Divergent validity for VOCI total score and subscales.

\begin{tabular}{|c|c|c|c|c|c|c|c|}
\hline Other Scales & Contamination & Checking & Obsessions & Hoarding & Just Right & Indecisiveness & Total \\
\hline BDI-II & 0.338 & 0.353 & 0.594 & 0.284 & 0.382 & 0.424 & 0.511 \\
\hline BAI & 0.293 & 0.379 & 0.492 & 0.366 & 0.401 & 0.412 & 0.491 \\
\hline PSWQ & 0.360 & 0.395 & 0.486 & 0.286 & 0.436 & 0.469 & 0.512 \\
\hline
\end{tabular}

Table 7. Varimax-rotated five-factor solution for VOCI-Persian items.

\begin{tabular}{|c|c|c|c|c|c|c|}
\hline $\begin{array}{c}\text { Factors } \\
\text { (subscale) }\end{array}$ & Factor 1 & Factor 2 & Factor 3 & Factor 4 & Factor 5 & $\begin{array}{c}\text { Factor structures } \\
\text { or } \mathrm{h}^{2}\end{array}$ \\
\hline \multirow{15}{*}{ Contamination } & 3 & & & & & 0.473 \\
\hline & 8 & & & & & 0.698 \\
\hline & 9 & & & & & 0.357 \\
\hline & 13 & & & & & 0.706 \\
\hline & 15 & & & & & 0.481 \\
\hline & 19 & & & & & 0.485 \\
\hline & 23 & & & & & 0.613 \\
\hline & 24 & & & & & 0.513 \\
\hline & 26 & & & & & 0.582 \\
\hline & 31 & & & & & 0.566 \\
\hline & 32 & & & & & 0.594 \\
\hline & 36 & & & & & 0.687 \\
\hline & 39 & & & & & 0.510 \\
\hline & 44 & & & & & 0.636 \\
\hline & 50 & & & & & 0.583 \\
\hline
\end{tabular}




\section{Continued}

\begin{tabular}{|c|c|c|c|c|c|}
\hline \multirow{9}{*}{ Checking } & 7 & & & & 0.645 \\
\hline & 18 & & & & 0.437 \\
\hline & 20 & & & & 0.794 \\
\hline & 33 & & & & 0.825 \\
\hline & 37 & & & & 0.702 \\
\hline & 38 & & & & 0.537 \\
\hline & 41 & & & & 0.759 \\
\hline & 43 & & & & 0.873 \\
\hline & 47 & & & & 0.632 \\
\hline \multirow{14}{*}{ Obsession } & & 2 & & & 0.617 \\
\hline & & 6 & & & 0.514 \\
\hline & & 12 & & & 0.670 \\
\hline & & 16 & & & 0.572 \\
\hline & & 25 & & & 0.395 \\
\hline & & 27 & & & 0.610 \\
\hline & & 28 & & & 0.710 \\
\hline & & 29 & & & 0.695 \\
\hline & & 30 & & & 0.549 \\
\hline & & 34 & & & 0.609 \\
\hline & & 40 & & & 0.697 \\
\hline & & 46 & & & 0.628 \\
\hline & & 52 & & & 0.574 \\
\hline & & 54 & & & 0.499 \\
\hline \multirow{7}{*}{ Hoarding } & & & 10 & & 0.594 \\
\hline & & & 22 & & 0.629 \\
\hline & & & 35 & & 0.640 \\
\hline & & & 42 & & 0.492 \\
\hline & & & 45 & & 0.678 \\
\hline & & & 49 & & 0.539 \\
\hline & & & 51 & & 0.660 \\
\hline \multirow{10}{*}{$\begin{array}{l}\text { Indecisiveness/ } \\
\text { Just right }\end{array}$} & & & & 1 & 0.503 \\
\hline & & & & 4 & 0.718 \\
\hline & & & & 5 & 0.412 \\
\hline & & & & 11 & 0.731 \\
\hline & & & & 14 & 0.635 \\
\hline & & & & 17 & 0.747 \\
\hline & & & & 21 & 0.493 \\
\hline & & & & 48 & 0.647 \\
\hline & & & & 53 & 0.396 \\
\hline & & & & 55 & 0.526 \\
\hline
\end{tabular}


The English version of VOCI as the originators describe, after a re-organization the subscales based on their hypothetical factor structure, included Contamination (12 items), Checking (6 items), Obsessions (12 items), Hoarding (7 items), Just Right (12 items), and Indecisiveness (6 items). However, our EFA yielded 5 components (subscales). The components are presented in the following section. The items which have been shown as bold present the items which have been indicated in the original English version of VOCI.

\section{The Component 1 (15 items)}

This component corresponds roughly to Contamination subscale of the original English VOCI.

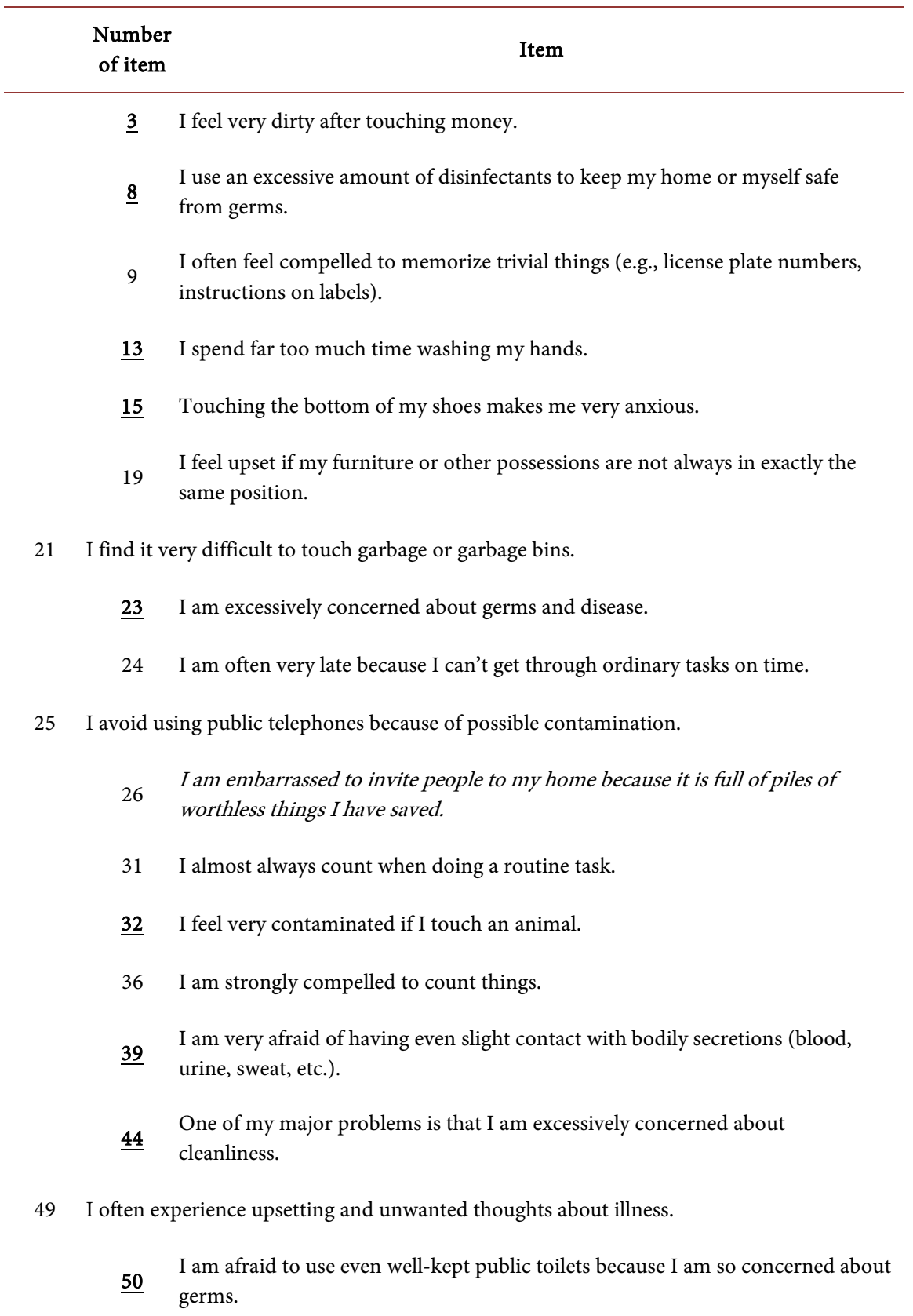


Items 9 "I often feel compelled to memorize trivial things (e.g. license plate number instructions on labels)", item 19 "I feel upset if my furniture or other possessions are not always in exactly the same position" Item 24 "I am often very late because I can't get through ordinary task on time", and 36 "I am strongly compelled to count things," all four belong to Just Right subscale in the original VOCI. Items 26 "I am embarrassed to invite people to my home because it is full of piles or worthless things I have saved", and item 31 "I almost always count when doing a routine task" belong to hoarding and Indecisiveness subscales, respectively in the original VOCI. On the other hand, there are 3 items, 21, 25, and 49 from the Contamination subscale of VOCI, which are missing in this component:

\begin{tabular}{cc}
\hline Number of item & Item \\
\hline 21 & I find it very difficult to touch garbage or garbage bins. \\
25 & I avoid using public telephones because of possible contamination. \\
49 & I often experience upsetting and unwanted thoughts about illness. \\
\hline
\end{tabular}

The Component 2 (9 items)

\begin{tabular}{|c|c|}
\hline Number of item & Item \\
\hline$\underline{7}$ & $\begin{array}{l}\text { I repeatedly check and recheck things like taps and switches after turning } \\
\text { them off. }\end{array}$ \\
\hline$\underline{18}$ & $\begin{array}{l}\text { I feel compelled to follow a very strict routine when doing ordinary } \\
\text { things. }\end{array}$ \\
\hline$\underline{20}$ & $\begin{array}{l}\text { I repeatedly check that my doors or windows are locked, even though I try } \\
\text { to resist the urge to do so. }\end{array}$ \\
\hline$\underline{33}$ & One of my major problems is repeated checking. \\
\hline$\underline{37}$ & $\begin{array}{l}\text { I repeatedly check that my stove is turned off, even though I resist the urge } \\
\text { to do so. }\end{array}$ \\
\hline 38 & $\begin{array}{l}\text { I get very upset if I can't complete my bedtime routine in exactly the same } \\
\text { way every night. }\end{array}$ \\
\hline$\underline{41}$ & I spend a lot of time every day checking things over and over again. \\
\hline$\underline{43}$ & $\begin{array}{l}\text { I frequently have to check things like switches, faucets, appliances, and } \\
\text { doors several times. }\end{array}$ \\
\hline 47 & $\begin{array}{l}\text { I tend to get behind in my work because I repeat the same thing over and } \\
\text { over again. }\end{array}$ \\
\hline
\end{tabular}

This component contains all 6 items (shown as bold and underlined) that have been categorized as checking in the original English VOCI. But there are 3 items that came from other original Just Right subscale (items 18, 38, and 47): 


\begin{tabular}{cl}
\hline Number of item & \multicolumn{1}{c}{ Item } \\
\hline 18 & I feel compelled to follow a very strict routine when doing ordinary things. \\
$\underline{\mathbf{3 8}}$ & $\begin{array}{l}\text { I get very upset if I can't complete my bedtime routine in exactly the same } \\
\text { way every night. }\end{array}$ \\
47 & $\begin{array}{l}\text { I tend to get behind in my work because I repeat the same thing over and } \\
\text { over again. }\end{array}$ \\
\hline
\end{tabular}

\section{The Component 3 (14 items)}

\begin{tabular}{|c|c|}
\hline Number of item & Item \\
\hline$\underline{2}$ & I am often upset by my unwanted thoughts of using a sharp weapon. \\
\hline$\underline{6}$ & $\begin{array}{l}\text { I repeatedly experience the same unwanted thought or image about an } \\
\text { accident. }\end{array}$ \\
\hline$\underline{12}$ & $\begin{array}{l}\text { I find that almost every day I am upset by unpleasant thoughts that come } \\
\text { into my mind against my will. }\end{array}$ \\
\hline$\underline{16}$ & I am often upset by my unwanted thoughts or images of sexual acts. \\
\hline 25 & I avoid using public telephones because of possible contamination. \\
\hline$\underline{27}$ & I repeatedly experience the same upsetting thought or image about death. \\
\hline$\underline{28}$ & $\begin{array}{l}\text { I am often upset by unwanted thoughts or images of blurting out obscenities } \\
\text { or insults in public. }\end{array}$ \\
\hline 29 & I worry far too much that I might upset other people. \\
\hline$\underline{30}$ & $\begin{array}{l}\text { I am often frightened by unwanted urges to drive or run into oncoming } \\
\text { traffic. }\end{array}$ \\
\hline$\underline{34}$ & I often experience upsetting and unwanted thoughts about losing control. \\
\hline$\underline{40}$ & I am often very upset by my unwanted impulses to harm other people. \\
\hline$\underline{46}$ & $\begin{array}{l}\text { I repeatedly experience upsetting and unacceptable thoughts of a religious } \\
\text { nature. }\end{array}$ \\
\hline$\underline{52}$ & I repeatedly experience upsetting and unwanted immoral thoughts. \\
\hline $5 \underline{4}$ & I am often upset by unwanted urges to harm myself. \\
\hline
\end{tabular}

This component correspond the original obsessions subscale of VOCI, which include 12 items. We have 2 items coming from the contamination subscale (item 25), and Indecisiveness subscale (item 29):

\begin{tabular}{cl}
\hline Number of item & Item \\
\hline 25 & I avoid using public telephones because of possible contamination. \\
29 & I worry far too much that I might upset other people. \\
\hline
\end{tabular}

\section{The Component 4 (7 items)}




\begin{tabular}{|c|c|c|}
\hline & $\begin{array}{l}\text { Number } \\
\text { of item }\end{array}$ & Item \\
\hline \multirow{5}{*}{26} & $\underline{10}$ & $\begin{array}{l}\text { I have trouble carrying out normal household activities because my home is so } \\
\text { cluttered with things I have collected. }\end{array}$ \\
\hline & $\underline{22}$ & I become very tense or upset when I think about throwing anything away. \\
\hline & \multicolumn{2}{|c|}{$\begin{array}{l}\text { I am embarr } \\
\text { have saved. }\end{array}$} \\
\hline & $\underline{35}$ & I find it almost impossible to decide what to keep and what to throw away. \\
\hline & $\underline{42}$ & $\begin{array}{l}\text { I have great trouble throwing anything away because I am very afraid of being } \\
\text { wasteful. }\end{array}$ \\
\hline \multirow{3}{*}{49} & $\underline{45}$ & $\begin{array}{l}\text { I feel compelled to keep far too many things like old magazines, newspapers, and } \\
\text { receipts because I am afraid I might need them in the future. }\end{array}$ \\
\hline & \multicolumn{2}{|c|}{ I often experience upsetting and unwanted thoughts about illness. } \\
\hline & $\underline{51}$ & $\begin{array}{l}\text { Although I try to resist, I feel compelled to collect a large quantity of things } \\
\text { I never actually use. }\end{array}$ \\
\hline
\end{tabular}

This component is equivalent roughly to the Hoarding subscale of the original English VOCI. Item 49 "I often experience upsetting and unwanted thought about illness" belongs to the Contamination subscale in the original English subscale. Item 26 "I am embarrassed to invite people to my home because it is full of piles of worthless things I have saved" from the Hoarding subscale of the original English VOCI is missing from our component 4, which has appeared in our component 1.

\section{The Component 5 (10 items)}

\begin{tabular}{|c|c|c|}
\hline & $\begin{array}{c}\text { Number } \\
\text { of item }\end{array}$ & Item \\
\hline & 1 & I feel compelled to check letters over and over before mailing them. \\
\hline & $\underline{4}$ & I find it very difficult to make even trivial decisions. \\
\hline & 5 & I feel compelled to be absolutely perfect. \\
\hline & $\underline{11}$ & After I have decided something, I usually worry about my decision for a long time. \\
\hline & 14 & I often have trouble getting things done because I try to do everything exactly right. \\
\hline & $\underline{17}$ & I become very anxious when I have to make even a minor decision. \\
\hline & 21 & I find it very difficult to touch garbage or garbage bins. \\
\hline \multirow[t]{5}{*}{29} & \multicolumn{2}{|c|}{ I worry far too much that I might upset other people. } \\
\hline & \multicolumn{2}{|c|}{ I almost always count when doing a routine task. } \\
\hline & $\underline{48}$ & I try to put off making decisions because I'm so afraid of making a mistake. \\
\hline & 53 & One of my major problems is that I pay far too much attention to detail. \\
\hline & 55 & $\begin{array}{l}\text { I spend far too long getting ready to leave home each day because I have to do } \\
\text { everything exactly right. }\end{array}$ \\
\hline
\end{tabular}


This component corresponds roughly to the Indecisiveness subscale of the original English VOCI. Items 1, "I feel compelled to check letters over and over before mailing them", 5 "I feel compelled to be absolutely perfect", 14 "I often have trouble getting things done because I try to do everything exactly right", 53 "one of my major problems is that I pay far too much attention to detail", and 55 "I spend far too long getting ready to leave home each day because I have to do everything exactly right", all belong to Just Right subscale in original English VOCI.

Item 21, which was missing from our Contamination subscale, appears here in Indecisiveness component of our VOCI. There are two items 29 "I worry far too much that I right upset other people" and 31 "I almost always count when doing a routine talk" which appear in the original Indecisiveness subscale of VOCI, but are missing in our component 5 .

\section{Discussion and Conclusion}

Although VOCI has been regarded as a "promising new instrument for the assessment of a wide range of obsessional compulsive complaints", there are some concerns about factor structure of VOCI (Thordarson et al., 2004: p. 1309). Our study yielded five components or factors of Persian version of VOCI.

Component 1 consists 15 items and corresponds roughly to Contamination subscale of the original VOCI which has 12 items. Items 21, 25, and 49 from the Contamination subscale of VOCI, are missing in this component. The following items are common between our Component 3 and contamination subscale of original VOCI: $3,8,13,15,23,32,39,44$, and 50 . All of these items deal with washing, cleaning and concern about germs. The 3 items that are missing from this component are item 21, 25 and 49. It seems the statement "I find it very difficult" in Persian language has had implication of difficulty to make a decision.

We don't have any justification for item 25 which clearly deals with contamination. But again the word "avoidance" brings with itself a kind of concern which is not very unrelated to obsessions. But item 49 does not seem to do anything with contamination and it has become part of our Component 5, which is roughly similar to Hoarding subscale of the original VOCI. We don't have any justification for this item as belonging to our Hoarding component. The same problem exists with the original VOCI. Probably the appropriate place for this item would be Obsession subscale.

Component 2 (9 items) corresponds to Checking in the original version, but it has 3 more items coming from Just Right factor. These 3 items deal with strictness, completing routines and repeating the things which are all closely related to Checking. The relationship between feelings of incompleteness which occur mostly when things are not being done in just right position on the one hand and compulsive checking on the other hand, has been shown in some studies (e.g. Cougle et al., 2013). Therefore, either we can call this component as Checking and Just Right component or remove the latter terminology from the Persian version of VOCI. In support to present result, Gönner et al. (2010) also 
excluded all these three questions.

Most items of Component 3 (14 items) belong to Obsessions subscale of VOCI (12 items) but there are 2 items coming from the contamination subscale (item 25), and Indecisiveness subscale (item 29). Although item 25 is about contamination, it seems it implies a feeling of concerns and worries which is not solely unrelated to obsessions. Item 29 comes from Indecisiveness subscale. This item is dealing with worry about upsetting other people. Its face validity does not appear to be something related to indecisiveness but since Turner et al. (1992) review, studies have provided empirical support of commonalities between the cognitive phenomena of obsession and worry.

Component 4 (7 items) is equivalent to the Hoarding subscale of the original English VOCI (7 items). Six items are the same in both versions: 10, 22, 35, 42, 45 and 51 . But there is one item, item 49 ("I often experience upsetting and unwanted thoughts about illness") which appears in the Contamination subscale, not in Hoarding subscale of the original. In our study it shows itself in Hoarding subscale. As a matter of fact, this item has nothing to do with Hoarding or Contamination. On the other hand, there is an item, item 26 "I am embarrassed to invite people to my home because it is full of piles of worthless things I have saved", which is missing from our Component 5 and appeared in Component 3 (Contamination) of our version.

Component 5 (10 items) corresponds roughly to the Perfectionism/Indecisiveness of two identical original English VOCI factors (Indecisiveness with 6 and Just Right with 12 items). Out of 10 items in one single factor of present study, items 4,11,17, and 48 and items 1, 5, 14, 53 and 55 are the same as the two VOCI original identical factors in Indecisiveness and Just Right, respectively. But items 1, 5, 14, 53 and 55 all belong to Just Right subscale in the original VOCI and as the content of the items indicate they generally deal with exactness, completeness, and doing the things in right order. We may consider Indecisiveness and Just Right together as one component. Furthermore, we have item 21 "I find it very difficult to touch garbage or garbage bins" in this component, which belongs to Contamination subscale in the original version of VOCI. We don't have any explanation why this item has appeared here. The only thing that we can say is that the word "very difficult" seems to have an implicational relevance to the concepts of Just Right and Indecisiveness.

The other problem in this component is the items that are missing from our Component 5. They include items 9, 18, 24, 36, 38, 47, from Just Right and items 29 and 31 from Indecisiveness factors. Item 29 "I worry for too much that I might upset other people" has appeared in Component 3 in our version which is dealing with Obsessions. As explained before, worry in Iranian culture is much related to obsessions. Another item, item 31 "I almost always count when doing a routine task" has appeared in Component 1of our study which is dealing with Contamination. One possible explanation for this is that some OCD washers count when they wash their hands and the counting in this situation usually occurs in a fixed fashion regarding number and some other rituals. Therefore, Ira- 
nian subjects have related this item to Contamination which is not very unexpected.

The VOCI/Just Right is conceptually similar to Perfectionism/Certainty factor of Obsessional Beliefs Questionnaire (OBQ-44/PC) (35 OCCWG, 2005). Our clinical observation also shows individuals with perfectionism symptom have difficulty in decision making. The items in subscales of Perfectionism/Certainty and Just Right in both questionnaires need to be re-conceptualized and consider as a deserving OC subscale. Introducing Indecisiveness subscale of VOCI as a new independent subscale, which in our study did not loaded as an independent factor, need further research.

In sum, in Persian version of VOCI we ended up with 5 components or subscales: Contamination (15 items), Checking (9 items), Obsessions (14 items), Hoarding (7 items) and Indecisiveness/Just Right (10 items).

As Gönner et al. (2010) indicate the original VOCI seems to suffer from significant structural deficits, concerning subscales Obsessions, Indecisiveness, and Just Right. Our claim is not that the Persian version is without any deficits but we believe that some subscales such as Component 2 (Checking), Component 3 (Obsessions) and Component 4 (Hoarding) are relatively valid and reliable subscales of our Persian version of VOCI. As our study shows their test-retest reliabilities are $0.906,0.930$ and 0.901 , respectively. Regarding to convergent validity there were high correlations between these subscales and corresponding OCI-R subscales $(0.870,0.736$ and 0.722 , respectively). But we don't have satisfactory evidence about the factor structure regarding Component 3 (Contamination) and Component 4 (Indecisiveness/Just Right) subscales. Therefore, we need another study, starting from the translation and going through all of the stages necessary for validation and factor analysis. In our study on the Persian version of OCI-R there was just one item which did not fit well the original structure but regarding the VOCI there are many items that appeared in other subscales different from the original one as discussed before. For this and other theoretical and methodological reasons revision of VOCI has been suggested by different investigators (e.g. Gönner et al., 2010) and we strongly suggest such a revision as well.

Another major problem with VOCI and other non-dimensional measures as Abramowitz et al. (2010) indicate is that "these measures have a number of important drawbacks that detract from their ability to provide a time efficient, empirically consistent, and conceptually clear assessment of OC symptom severity" (p. 181). Based on such an evaluation they have introduced Dimensional Obsessive-Compulsive Scale. But this scale itself requires more evidence about the utility, feasibility and sensitivity to diagnosis and treatment.

\section{References}

Abramowitz, J. S., \& Foa, E. B. (1998). Worries and Obsessions in Individuals with Obsessive-Compulsive Disorder with and without Comorbid Generalized Anxiety Disorder. Behavior Research Therapy, 36, 695-700.

http://dx.doi.org/10.1016/S0005-7967(98)00058-8 
Abramowitz, J. S., Deacon, B., Olatunji, B., Wheaton, M. G., Berman, N., Losardo, D., Timpano, K., McGrath, P., Riemann, B., Adams, T., Bjorgvinsson, T., Storch, E. A., \& Hale, L. (2010). Assessment of Obsessive-Compulsive Symptom Dimensions: Development and Evaluation of the Dimensional Obsessive-Compulsive Scale. Psychological Assessment, 22, 180-198. http://dx.doi.org/10.1037/a0018260

Arjona, R. N., Avila, A. G., Lazaro, A. G., \& Romero, Y. P. (2009). Sanchiz propeiedades psicometricas del Vancouver Obsessional Compulsive Inventory (VOCI) en dos muestras no clinicas de poblacion espanola. Psicothema, 21, 646-651.

Beck, A. T., Epstein, N., Brown, G., \& Steer, R. A. (1988). An Inventory for Measuring Clinical Anxiety: Psychometric Properties. Journal of Consulting Clinical Psychology, 56, 893-897. http://dx.doi.org/10.1037/0022-006X.56.6.893

Beck, A. T., Steer, R. A., \& Gabrin, M. G. (1988). The Psychometric Properties of the Beck Depression Inventory: Twenty-Five Years of Evaluation. Clinical Psychology Review, 8, 77-100. http://dx.doi.org/10.1016/0272-7358(88)90050-5

Beck, A. T., Ward, C., Mendelson, M., Mock, J., \& Erbaugh, J. (1961). An Inventory of Measuring Depression. Archives of General Psychiatry, 4, 561-571. http://dx.doi.org/10.1001/archpsyc.1961.01710120031004

Cougle, J. R., Timpano, K. R., Sarawgi, S., Smith, C. M., \& Fitch, K. E. (2013). A Multi-Modal Investigation of the Roles of Distress Tolerance and Emotional Reactivity in Obsessive-Compulsive Symptoms. Anxiety, Stress, \& Coping, 26, 478-492. http://dx.doi.org/10.1080/10615806.2012.697156

Emmelkamp, P. M. G., Kraaijkamp, H. J. M., \& van den Hout, A. (1999). Assessment of Obsessive Compulsive Inventory: Development and Validation of a Short Version. Psychological Assessment, 14, 485-496.

Foa, E. B., Kozak, M. J., Foa, E. B., Huppert, J. D., Leiberg, S., Hajcak, G., Langner, R., Kichic, R., \& Salkovskis, P. M. (2002). The Obsessive-Compulsive Inventory: Development and Validation of a Short Version. Psychological Assessment, 14, 485-496. http://dx.doi.org/10.1037/1040-3590.14.4.485

Foa, E. B., Kozak, M. J., Salkovskis, P. M., Coles, M. E., \& Amir, N. (1998). The Validation of a New Obsessive-Compulsive Disorder Scale: The Obsessive-Compulsive Inventory. Psychological Assessment, 10, 206-214. http://dx.doi.org/10.1037/1040-3590.10.3.206

Ghassemzadeh, H., Bolhari, J., Birashk, B., \& Salavati, M. (2005a). Responsibility Attitude in a Sample of Iranian Obsessive-Compulsive Patients. International Journal of Social Psychiatry, 51, 13-22. http://dx.doi.org/10.1177/0020764005053266

Ghassemzadeh, H., Khamseh, A., \& Ebrahimkhani, N. (2005b). Demographic Variables and Clinical Features of Obsessive-Compulsive Disorder in Iran: A Second Report. In B. E. Ling (Ed.), Obsessive-Compulsive Disorder Research (pp. 243-271). New York: Nova Science Publishers, Inc.

Ghassemzadeh, H., Mojtabai, R., Karamghadiri, N., \& Ebrahimkhani, N. (2005c). Psychometric Properties of a Persian-Language Version of the Beck Depression Inventory: Second Edition: BDI-II-Persian. Depression and Anxiety, 21, 185-192.

http://dx.doi.org/10.1002/da.20070

Ghassemzadeh, H., Mojtabai, R., Khamseh, A., Ebrahimkhani, N., Issazadegan, A., \& Saif-No- bakht, Z. (2002). Symptoms of Obsessive-Compulsive Disorder in a Sample of Iranian Patients. International Journal of Social Psychiatry, 48, 20-28. http://dx.doi.org/10.1177/002076402128783055

Ghassemzadeh, H., Shams, G., Abedi, J., Karamghadiri, N., Ebrahimkhani, N., \& Rajabloo, M (2011). Psychometric Properties of a Persian-Language Version of the Obsessive-Compulsive Inventory-Revised: OCI-R-Persian. Psychology, 2, 210-215. http://dx.doi.org/10.4236/psych.2011.23032 
Gönner, S., Ecker, W., Leonhart, R., \& Limbacher, K. (2010). Multidimensional Assessment of OCD: Integration and Revision of the Vancouver Obsessional-Compulsive Inventory and the Symmetry Ordering and Arranging Questionnaire. Journal of Clinical Psychology, 66, 739-757.

Goodman, W. K., \& Price, L. H. (1998). Rating Scales for Obsessive-Compulsive Disorder. In M. A. Jenike, L. Bear, \& W. E. Minichiello (Eds.), Obsessive-Compulsive Disorders-Practical Management (pp. 97-117). St. Louis, MO: Mosby.

Hodgson, R. J., \& Rachman, S. (1977). Obsessional-Compulsive Complaints. Behaviour Research and Therapy, 15, 389-395. http://dx.doi.org/10.1016/0005-7967(77)90042-0

Kaviani, H., \& Mousavi, A. S. (2008). Psychometric Properties of the Persian Version of Beck Anxiety Inventory (BAI). Tehran University Medical Journal, 66, 136-140.

Leckman, J. F., Grice, D. E., Boardman, J., Zhang, H., Vitale, A., Bondi, C. et al. (1997). Symptoms of Obsessive-Compulsive Disorder. American Journal of Psychiatry, 154, 911-917. http://dx.doi.org/10.1176/ajp.154.7.911

Meyer, T. J., Miller, M. L., Metzger, R. L., \& Borkovec, T. D. (1990). Development and Validation of the Penn State Worry Questionnaire. Behaviour Research and Therapy, 28, 487-495. http://dx.doi.org/10.1016/0005-7967(90)90135-6

Obsessive Compulsive Cognitions Working Group (2005). Psychometrics Validation of the Obsessive Beliefs Questionnaire and the Interpretation of Intrusions InventoryPart 2: Factor Analysis and Testing of a Brief Version. Behavior Research and Therapy, 43, 1527-1542. http://dx.doi.org/10.1016/j.brat.2004.07.010

Radomsky, A. S., Alcolado, G. M., Abramowitz, J. S. et al. (2014). Part 1-You Can Run but You Can't Hide: Intrusive Thoughts on Six Continents. Journal of ObsessiveCompulsive and Related Disorders, 3, 269-279. http://dx.doi.org/10.1016/j.jocrd.2013.09.002

Radomsky, A. S., Ouimet, A. J., Ashbaugh, A. R., Lavoie, S. L., Parrish, C. L., \& O’Connor, K. P. (2006). Psychometric Properties of the French and English Versions of the Vancouver Obsessional-Compulsive Inventory and the Symmetry Ordering and Arranging Questionnaire. Cognitive Behaviour Therapy, 35, 164-173. http://dx.doi.org/10.1080/16506070600827198

Richter, M. A., Cox, B. J., \& Direnfeld, D. M. (1994). A Comparison of Three Assessment Instruments for Obsessive-Compulsive Symptoms. Journal of Behavior Therapy and Experimental Psychiatry, 25, 143-147. http://dx.doi.org/10.1016/0005-7916(94)90007-8

Shams, G., Esmaili, Y., Karamghadiri, N., Ebrahimkhani, N., Yousefi, Y., \& McKay, D. (2014). Factor Structure of the Persian Language Version of the Obsessive Beliefs Questionnaire-44 (OBQ-44) in Iranian Student Sample. Acta Medica Iranica, 52, 66-75.

Shams, G., Kaviani, H., Esmaili, Y., Ebrahimkhani, N., \& Amin Manesh, A. (2011). Psychometric Properties of the Persian Version of the Padua Inventory: Washington State University Revision (PI-WSUR). Iranian Journal of Psychiatry, 6, 12-18.

St. Clare, T. (2003). Assessment Procedures. In R. G. Menzies, \& P. de Silva (Eds.), Obsessive-Compulsive Disorder: Theory, Research and Treatment (pp. 239-257). West Sussex: John Wiley.

Storch, E. A., Benito, K., \& Goodman, W. (2011). Assessment Scales for ObsessiveCompulsive Disorder. Neuropsychiatry, 1, 243-250. http://dx.doi.org/10.2217/npy.11.22

Summerfeldt, L. J. (2004). Understanding and Treating Incompleteness in Obsessive-Compulsive Disorder. Journal of Clinical Psychology, 60, 1155-1168. http://dx.doi.org/10.1002/jclp.20080

Summerfeldt, L. J., Kloosterman, P. H., Parker, J. D. A., Antony, M. M., \& Swinson, R. P. 
(2001). Assessing and Validating the Obsessive-Compulsive-Related Construct of Incompleteness. Poster presented at the 62nd Annual Convention of the Canadian Psychological Association, Ste-Foy, Quebec.

Taylor, S. (1995). Assessment of Obsessions and Compulsions: Reliability, Validity, and Sensitivity to Treatment Effects. Clinical Psychology Review, 15, 261-296. http://dx.doi.org/10.1016/0272-7358(95)00015-H

Thordarson, D. S., Radomsky, A. S., Rachman, S., Shafran, R., Sawchuk, C. N., \& Hakstian, A. R. (2004). The Vancouver Obsessional Compulsive Inventory (VOCI). Behaviour Research and Therapy, 42, 1289-1314. http://dx.doi.org/10.1016/j.brat.2003.08.007

Turner, S. M., Beidel, D. C., \& Townsley, R. M. (1992). Social Phobia: A Comparison of Specific and Generalized Subtypes and Avoidant Personality Disorder. Journal of $A b$ normal Psychology, 101, 326-331. http://dx.doi.org/10.1037/0021-843X.101.2.326

Submit or recommend next manuscript to SCIRP and we will provide best service for you:

Accepting pre-submission inquiries through Email, Facebook, LinkedIn, Twitter, etc. A wide selection of journals (inclusive of 9 subjects, more than 200 journals)

Providing 24-hour high-quality service

User-friendly online submission system

Fair and swift peer-review system

Efficient typesetting and proofreading procedure

Display of the result of downloads and visits, as well as the number of cited articles Maximum dissemination of your research work

Submit your manuscript at: http://papersubmission.scirp.org/

Or contact psych@scirp.org 